Research Paper

\title{
Efificacy of Lamivudine or Entecavir on Acute Exacerbation of Chronic Hepatitis B
}

\section{Tatsuo Kanda ${ }^{1^{\star \star}}$, Masami Shinozaki ${ }^{2 *}$, Hidehiro Kamezaki ${ }^{1}$, Shuang Wu ${ }^{1}$, Shingo Nakamoto ${ }^{1}$, Makoto Arai', Keiichi Fujiwara', Nobuaki Goto ${ }^{2}$, Fumio Imazeki' and Osamu Yokosuka'}

1. Department of Medicine and Clinical Oncology, Chiba University, Graduate School of Medicine, 1-8-1 Inohana, Chuo-ku, Chiba 260-8670, Japan.

2. Department of Medicine, Numazu City Hospital, Numazu, Shizuoka 410-0302, Japan.

* These authors contributed equally to this article.

$\triangle$ Corresponding author: Tatsuo Kanda, MD, PhD, Associate Professor, Department of Medicine and Clinical Oncology, Graduate School of Medicine, Chiba University, 1-8-1 Inohana, Chuo-ku, Chiba 260-8677, Japan. Tel.: +81-43-226-2086; Fax: +81-43-226-2088; E-mail: kandat-cib@umin.ac.jp

(c) Ivyspring International Publisher. This is an open-access article distributed under the terms of the Creative Commons License (http://creativecommons.org/ licenses/by-nc-nd/3.0/). Reproduction is permitted for personal, noncommercial use, provided that the article is in whole, unmodified, and properly cited.

Received: 2011.09.21; Accepted: 2011.10.31; Published: 2011.11.10

\begin{abstract}
Background/Aims: Spontaneous acute exacerbation of chronic hepatitis B virus (HBV) infection occasionally occurs in its natural history, sometimes leading rapidly to fatal hepatic failure. We compared the effects of lamivudine (LAM) with those of entecavir (ETV) treatments in acute exacerbation of chronic hepatitis B with $500 \mathrm{IU} / \mathrm{L}$ or higher alanine aminotransferase (ALT) levels.

Methods: Thirty-four patients with acute exacerbation were consecutively treated with LAM /ETV. Their clinical improvements were compared.

Results: Among LAM-treated and ETV-treated patients, none showed a reduction of $<1$ log $\mathrm{IU} / \mathrm{mL}$ in HBV DNA after I or 3 months of treatment. Initial virological response, defined as a reduction of $4 \log \mathrm{IU} / \mathrm{mL}$ in HBV DNA at 6 months, with LAM and ETV, respectively, was $83.3 \%$ and $100 \%$. One LAM patient developed hepatic encephalopathy, but all patients in both groups survived. Twelve months after treatment, $41.6 \%$ of 24 LAM group patients switched to another drug or added adefovir to their treatment due to the emergence of LAM-resistant mutants. On the other hand, patients receiving ETV did not need to change drugs.

Conclusions: ETV appears to be as effective as LAM in the treatment of patients with acute exacerbation of chronic hepatitis B. Clinicians should carefully start to treat these patients as soon as possible.
\end{abstract}

Key words: acute exacerbation, ALT, entecavir, HBV, lamivudine

\section{INTRODUCTION}

Chronic hepatitis B infection is associated with the development of hepatocellular carcinoma [1]. Infection with hepatitis B virus (HBV) also leads to wide a spectrum of liver injury, including acute, self-limited infection, fulminant hepatitis, and chronic hepatitis with progression to cirrhosis and liver fail- ure, as well as to an asymptomatic chronic carrier state $[2,3]$.

Reactivation of hepatitis B is a well-characterized syndrome marked by the abrupt reappearance or rise of HBV DNA in the serum of a patient with previously inactivated or resolved HBV infection [4]. Reac- 
tivation is often spontaneous, but can also be triggered by cancer chemotherapy and immune suppression. Spontaneous acute exacerbation of chronic hepatitis B infection is seen with a cumulative probability of $15-37 \%$ after 4 years of follow-up [5]. Prognosis is generally poor in $\mathrm{HBV}$ carriers with spontaneous acute exacerbation together with high alanine aminotransferase (ALT) levels, jaundice, and liver failure $[4,6,7]$. This condition has been defined as acute-on-chronic liver failure according to a recent Asia-Pacific consensus recommendation [8]. Acute exacerbation occasionally leads to a critical scenario, meaning that clinicians need to treat this condition immediately.

Lamivudine (LAM) is a reverse-transcriptase inhibitor of viral DNA polymerase with an excellent profile of safety and tolerability, causing inhibition of viral replication, and it is approved for antiviral treatment of hepatitis B patients [9, 10]. LAM suppresses serum HBV DNA values in up to $98 \%$ of patients within a median period of 4 weeks, leading to aminotransferase normalization, increased hepatitis B e antigen (HBeAg) seroconversion rate, and improvement of histological parameters [11, 12]. A study from Taiwan showed that LAM had a survival benefit and was effective for patients with baseline bilirubin levels below $20 \mathrm{mg} / \mathrm{dL}$ [7].

Entecavir (ETV), a deoxyguanosine analogue, is a potent and selective inhibitor of HBV replication; its in vitro potency is 100 - to 1,000 -fold greater than that of LAM, and it has a selectivity index (concentration of drug reducing the viable cell number by $50 \%$ $\left[\mathrm{CC}_{50}\right] /$ concentration of drug reducing viral replication by $\left.50 \%\left[\mathrm{EC}_{50}\right]\right)$ of $\sim 8,000[13,14]$. At present, the Japanese national health insurance system approves ETV as the first-line therapy for chronic hepatitis B, although some patients are treated with standard interferon-alfa. ETV is a nucleoside analogue (NUC) belonging to a new subgroup, cyclopentane [15], and it has been shown to be highly effective in suppressing HBV replication to an undetectable level and normalizing ALT, although NUCs do not eradicate the virus. ETV develops less resistance than LAM.

We undertook a retrospective study to compare the efficacy of LAM with that of ETV in the reduction of HBV DNA levels and associated improvement in disease severity and biochemical recovery in patients with acute exacerbation together with higher ALT levels due to $\mathrm{HBV}$ reactivation.

\section{MATERIALS AND METHODS Patients}

A retrospective analysis of LAM/ETV-treated chronic hepatitis B patients at Chiba University Hos- pital and Numazu City Hospital, Japan, between May 2003 and December 2009 was performed. The inclusion criteria were: acute exacerbation of chronic hepatitis B characterized by an elevation of ALT level $\geq$ $500 \mathrm{IU} / \mathrm{L}$ along with HBV DNA $\geq 4.5 \mathrm{log} \mathrm{IU} / \mathrm{mL}$ presenting in a patient with diagnosed chronic liver disease. The exclusion criteria were: acute hepatitis $B$, superinfection with other viruses (hepatitis E, A, D, or C), other causes of chronic liver failure [16, 17], coexistent hepatocellular carcinoma, portal thrombosis, coexistent renal impairment, pregnancy, coinfection with human immunodeficiency virus (HIV), or patients who had received a previous course of NUC treatment. This retrospective study protocol conforms to the ethical guidelines of the 1975 Declaration of Helsinki as reflected in a priori approval by the Ethics Committee of Chiba University, Graduate School of Medicine [18].

\section{Baseline assessment of patients}

Retrospectively collected data included patient demographics, clinical findings, all laboratory variables including virological tests and abdominal ultrasound. HBsAg, HBeAg, anti-HBe antibody and immunoglobulin M (IgM) anti-HBc antibody were determined by ELISA (Abbott, Chicago, IL, USA) or CLEIA (Fujirebio, Tokyo, Japan) [19]. HBV genotype was determined from patients' sera by ELISA (Institute of Immunology, Tokyo, Japan) as reported by Usuda et al [20]. HBV DNA was measured by Roche Amplicor ${ }^{\mathrm{TM}}$ PCR assay (detection limits: $2.6 \mathrm{log}$ IU/mL; Roche Diagnostics, Tokyo, Japan).

\section{Definitions}

Primary antiviral treatment failure was defined as a reduction of $<1 \log \mathrm{IU} / \mathrm{mL}$ in HBV DNA after 3 months of therapy. Initial virological response (IVR) was defined as a reduction of $\geq 4 \log \mathrm{IU} / \mathrm{mL}$ in HBV DNA after 6 months of therapy [21].

\section{Follow-up}

Clinical assessment and routine investigations were done every 15 days or every month for at least 6 months. HBV DNA measurements were repeated monthly.

\section{Statistical analysis}

Statistical analyses were performed using Microsoft Excel 2010 for Windows ${ }^{\mathrm{TM}} 7$ and StatView 5 (SAS Institute Inc, Cary, NC). Continuous variables were expressed as mean \pm standard deviation and were compared by two-factor analysis of variance (ANOVA) and two-way repeated measures ANOVA. Categorical variables were compared by Chi-square 
test. Baseline was taken as the date when the first dose of LAM/ETV was administered. Statistical significance was considered at a $P$-value $<0.05$.

\section{RESULTS}

\section{Patients}

Between May 2003 and December 2009, 34 patients with spontaneous acute exacerbation of chronic hepatitis B, with ALT levels $\geq 500 \mathrm{IU} / \mathrm{mL}$ and treated with LAM or ETV, were consecutively enrolled and retrospectively analyzed. $24(70.5 \%)$ were treated with LAM at $100 \mathrm{mg}$ daily and $10(29.4 \%)$ were treated with ETV at $0.5 \mathrm{mg}$ daily. All patients were followed for at least 6 months. Mean follow-up in the LAM and ETV groups was $55.5 \pm 25.4$ and $16.5 \pm 9.9$ months, respectively.

\section{Baseline characteristics}

Baseline characteristics in the two patient groups were similar (Table 1). Median age was 37 (21-73) years and $79.4 \%$ were men. One patient of the LAM group developed hepatic encephalopathy, but recovered. All patients in both groups survived. At admission, the serological profile showed HBsAg positivity in all $34(100 \%) ; 22(64.7 \%)$ were HBeAg positive. The median HBV DNA level was $7.4 \log \mathrm{IU} / \mathrm{mL}$ in the LAM group and $7.9 \log \mathrm{IU} / \mathrm{mL}$ in the ETV group (Table 1).

Table I Demographic, Clinical, and Laboratory Variables of Patients at Entry.

\begin{tabular}{|c|c|c|c|c|}
\hline Parameters & $\begin{array}{l}\text { Total Pa- } \\
\text { tients }(\mathrm{N}=34)\end{array}$ & LAM (N=24) & ETV $(\mathrm{N}=10)$ & $P$-value \\
\hline Age (years) & 37 (21-73) & 37 (21-73) & 39 (24-67) & NS \\
\hline Male (\%) & $27(79.4)$ & $18(75)$ & $9(90)$ & NS \\
\hline $\begin{array}{l}\text { Cirrhosis } \\
(+/-)\end{array}$ & $2 / 32$ & $2 / 22$ & $0 / 10$ & NS \\
\hline ALT (IU/L) & $\begin{array}{l}986 \\
(523-2,450)\end{array}$ & $\begin{array}{l}995 \\
(523-2,450)\end{array}$ & $\begin{array}{l}1,046 \\
(523-2,140)\end{array}$ & NS \\
\hline $\begin{array}{l}\text { T. Bil } \\
(\mathrm{mg} / \mathrm{dL})\end{array}$ & $2.0(0.8-22.0)$ & $2.4(0.8-20.6)$ & $1.6(1.9-22.0)$ & NS \\
\hline PT (\%) & $83(24-121)$ & 81.5 (24-119) & $83.6(35-121)$ & NS \\
\hline $\begin{array}{l}\mathrm{HBeAg} \\
(+/-)\end{array}$ & $22 / 12$ & $18 / 6$ & $4 / 6$ & NS \\
\hline $\begin{array}{l}\text { HBV DNA } \\
(\log I U / m L)\end{array}$ & $7.6(4.8-8.7)$ & $7.4(5.2-8.7)$ & $7.9(4.8-8.7)$ & NS \\
\hline
\end{tabular}

LAM, lamivudine; ETV, entecavir; ALT, alanine aminotransferase; T. BIL, total bilirubin; PT, prothrombin time; NS, statistically not significant.

\section{Reduction in HBV DNA of total patients}

LAM significantly reduced HBV DNA levels from baseline $7.24 \log \mathrm{IU} / \mathrm{mL}$ to $3.27 \log \mathrm{IU} / \mathrm{mL}$ at 1 month $(P<0.001)$, to $2.21 \log \mathrm{IU} / \mathrm{mL}$ at 3 months $(P<$
$0.001)$, and to $1.53 \log \mathrm{IU} / \mathrm{mL}$ at 6 months $(P<0.001)$. ETV also significantly reduced HBV DNA levels from baseline $7.56 \log \mathrm{IU} / \mathrm{mL}$ to $3.12 \log \mathrm{IU} / \mathrm{mL}$ at 1 month $(P<0.001)$, to $2.14 \log \mathrm{IU} / \mathrm{mL}$ at 3 months $(P<0.001)$, and to $1.77 \log \mathrm{IU} / \mathrm{mL}$ at 6 months $(P<0.001)$. There were no differences in HBV DNA levels from baseline to 6 months between the two groups. None with primary antiviral treatment failure was identified in either group. There were no significant differences in IVR between the two groups (Figure 1).

\section{Reduction in ALT levels of total patients}

LAM significantly reduced ALT levels from baseline $1,130 \mathrm{IU} / \mathrm{mL}$ to $102(P<0.001)$ at 1 month, to $28.6(P<0.001)$ at 3 months, and to $23.1(P<0.001)$ at 6 months. ETV also significantly reduced ALT levels from baseline $1,210 \mathrm{IU} / \mathrm{mL}$ to $117(P<0.001)$ at 1 month, to $25(P<0.001)$ at 3 months, and to $24.4(P<$ $0.001)$ at 6 months. There were no differences in ALT levels from baseline to 6 months between the two groups (Figure 2).

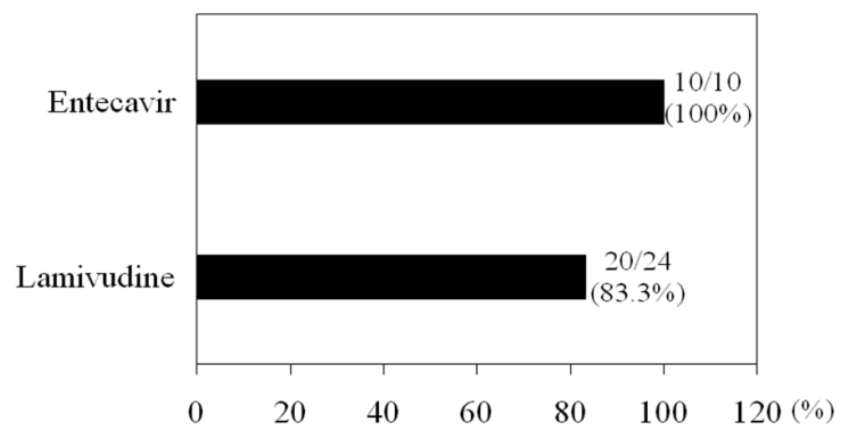

Figure I Initial virological response (IVR). IVR was defined as a reduction of $\geq 4 \log I U / \mathrm{mL}$ in HBV DNA after 6 months of therapy [2I].

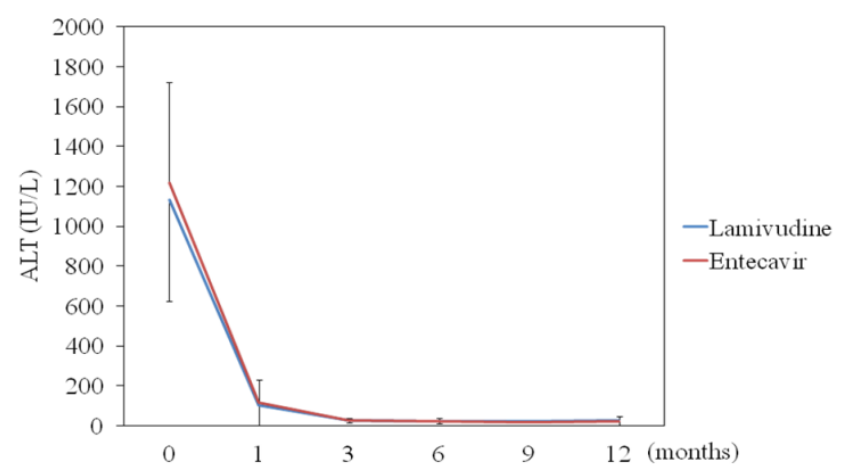

Figure 2 Efficacy of lamivudine and entecavir for ALT levels. Lamivudine $(N=24)$ vs. entecavir $(N=10)$; data are shown as mean \pm SD. 


\section{Reduction in HBV DNA of HBeAg-positive patients}

It has been demonstrated that the levels of HBV DNA in the HBeAg-positive phase were generally higher than those in the ant-HBe-positive phase [19, 22]. $\mathrm{HBeAg}$ positivity is also associated with $\mathrm{HBV}$ viremia and increased ALT levels in $\mathrm{HIV} / \mathrm{HBV}$ co-infected patients [23]. Next, we compared the response to LAM or ETV in 18 or $4 \mathrm{HBeAg}$-positive patients, respectively (Table 2 ). LAM significantly reduced HBV DNA levels from baseline $7.52 \log \mathrm{IU} / \mathrm{mL}$ to $3.35 \log \mathrm{IU} / \mathrm{mL}(P<0.001)$ at 1 month, to $2.38 \log$ $\mathrm{IU} / \mathrm{mL}(P<0.001)$ at 3 months, and to $1.55 \log \mathrm{IU} / \mathrm{mL}$ $(P<0.001)$ at 6 months. ETV also significantly reduced HBV DNA levels from baseline $8.42 \log \mathrm{IU} / \mathrm{mL}$ to 3.87 $\log \mathrm{IU} / \mathrm{mL}(P<0.001)$ at 1 month, to $2.90 \log \mathrm{IU} / \mathrm{mL}$ $(P<0.001)$ at 3 months, and to $2.22 \log \mathrm{IU} / \mathrm{mL}(P<$ $0.001)$ at 6 months. There were no differences in HBV DNA levels from baseline to 6 months between the two groups. Primary antiviral treatment failure was not observed in either group. Four patients in the LAM group did not achieve IVR.

Table 2 Demographic, Clinical, and Laboratory Variables of $\mathrm{HBeAg}$-positive Patients at Entry.

\begin{tabular}{lllll}
\hline Parameters & $\begin{array}{l}\text { Total Patients } \\
(\mathrm{N}=22)\end{array}$ & LAM (N=18) & ETV (N=4) & P-value \\
\hline Age (years) & $34.5(21-51)$ & $36.5(21-51)$ & $30(24-33)$ & NS \\
Male (\%) & $18(81.8)$ & $14(77.7)$ & $4(100)$ & NS \\
Cirrhosis (+/-) & $1 / 21$ & $1 / 17$ & $0 / 4$ & NS \\
ALT (IU/L) & 1,030 & 1,990 & 1,363 & NS \\
& $(523-2,450)$ & $(523-2,450)$ & $(980-1,620)$ & \\
T. Bil (mg/dL) & $1.75(0.8-20.6)$ & $2.0(0.8-20.6)$ & $1.5(1.0-18.7)$ & NS \\
PT (\%) & $77(24-119)$ & $73.6(24-119)$ & $95.0(44.1-113)$ & NS \\
HBeAg (+) & 22 & 18 & 4 & \\
HBV DNA & $7.6(5.5-8.8)$ & $7.6(5.5-8.7)$ & $8.6(7.6-8.7)$ & NS \\
$(\log$ IU/mL) & & & & \\
\hline
\end{tabular}

LAM, lamivudine; ETV, entecavir; ALT, alanine aminotransferase; T. BIL, total bilirubin; PT, prothrombin time; NS, statistically not significant.

\section{Reduction in ALT levels of HBeAg-positive patients}

LAM significantly reduced ALT levels from baseline $1,150 \mathrm{IU} / \mathrm{mL}$ to $84(P<0.001)$ at 1 month, to $27.5(P<0.001)$ at 3 months, and to $22.0(P<0.001)$ at 6 months. ETV also significantly reduced ALT levels from baseline $1,460 \mathrm{IU} / \mathrm{mL}$ to $230(P=0.0038)$ at 1 month, to $22.2(P=0.0016)$ at 3 months, and to $24.0(P$ $=0.0016)$ at 6 months. At 1 month after treatment, the ALT levels of the LAM groups were lower than those of the ETV group $(P<0.0001)$ (Figure 3$)$. During follow-up periods, 10 and 1 sero-converters of $\mathrm{HBeAg}$ to
anti-HBe antibody phase were seen in 18 LAM-treated and in 4 ETV-treated patients, respectively.

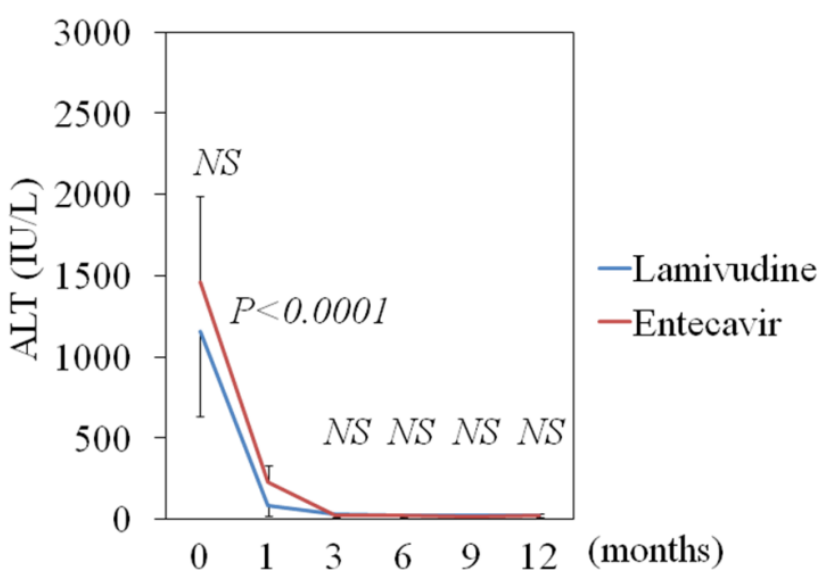

Figure 3 Efficacy of lamivudine and entecavir for ALT levels in $\mathrm{HBeAg}$-positive patients. Lamivudine $(\mathrm{N}=18)$ vs. entecavir $(N=4)$; data are shown as mean $\pm S D$.

\section{Safety}

No patient stopped taking medications. Twelve months after treatment, 10 of 24 patients $(41.6 \%)$ in the LAM group switched from LAM to ETV $(n=4)$ or added adefovir $(n=6)$ due to the emergence of LAM-resistant mutants. On the other hand, patients receiving ETV did not need to change their medication.

\section{DISCUSSION}

The present study compared the use of NUCs, LAM and ETV, for the treatment of acute exacerbation of chronic hepatitis B. The results clearly showed significant benefits of a rapid reduction of HBV DNA levels, compared with untreated patients in a previous report [4].

It was reported that ETV treatment is associated with increased short-term mortality in patients with severe acute exacerbation of chronic hepatitis B, but that it achieves better virological response in the long run [24]. We used LAM or ETV for patients with acute exacerbation of chronic hepatitis B presenting with ALT $\geq 500 \mathrm{IU} / \mathrm{L}$ in the present study. The effects of LAM on HBV DNA levels were the same as those of ETV (Figure 1). But the effects of LAM on ALT levels after 1 month were stronger than those of ETV in HBeAg-positive patients (Figure 3). In spite of the limited number of these patients, the effects were possibly related to immunomodulating activities of LAM [25]. The patients' prognoses were more favorable than in the previous report [4]. This might have 
depended on the fact that, in the present study, treatment was begun as soon as possible, and some patients may have had a milder grade of acute exacerbation of chronic hepatitis B than those in the previous report [4]. We believe that patients with acute exacerbation of chronic hepatitis $B$ need to be subjected to treatment as promptly as possible.

The major routes of HBV infection in our country have been mother-to-child transmission and blood transfusion. However, cases with HBV transmitted through sexual contact are increasing, especially among HIV-1-seropositive patients [26]. One should bear in mind that knowledge about interactions between ETV and anti-HIV nucleoside analogues is limited [27]. Because long-term use of LAM induces LAM-resistant mutants [28], we can only use LAM for short-term treatment of patients with acute exacerbation of chronic hepatitis B. On the other hand, the present study also revealed that patients receiving ETV did not need to change drugs.

Recently, there have been several reports that reactivation of $\mathrm{HBV}$ is a fatal complication following systemic chemotherapy or other immunosuppressive therapy including rituximab and steroid therapies mainly in HBsAg-positive and -negative lymphoma patients. It is important to enable early diagnosis of $\mathrm{HBV}$ reactivation as well as initiation of antiviral therapy $[29,30]$.

In conclusion, ETV appears to be as effective as LAM in the treatment of patients with acute exacerbation of chronic hepatitis B. Clinicians should start to treat these patients with NUCs as soon as possible.

\section{ACKNOWLEDGEMENTS}

This work was supported by the Japan Science and Technology Agency, Ministry of Education, Culture, Sports, Science and Technology, Japan [21590829 (TK), 21590828 (FI), and 21390225 (OY)], a grant from the Japan Society of Hepatology (TK), and a grant from Chiba University Young Research-Oriented Faculty Member Development Program in Bioscience Areas (TK).

This work was partly presented at 21st Conference of the Asian Pacific Association for the Study of the Liver on 17 February 2011, Queen Sirkit National Convention Center, Bangkok, Thailand.

\section{ABBREVIATIONS}

ETV: Entecavir; HIV: Human immunodeficiency virus; IVR: Initial virological response; LAM: Lamivudine; NUC: Nucleoside analogue.

\section{CONFLICT OF INTEREST}

The authors have declared that no conflict of interest exists.

\section{REFERENCES}

1. Di Bisceglie AM. Hepatitis B and Hepatocellular Carcinoma. Hepatology. 2009; 49 (5 Suppl): S56-S60.

2. Omata M, Ehata T, Yokosuka O, et al. Mutations in the precore region of hepatitis $B$ virus DNA in patients with fulminant and severe hepatitis. N Engl J Med. 1991; 324: 1699-1704.

3. Liang TJ, Hasegawa K, Rimon N, et al. A hepatitis B virus mutant associated with an epidemic of fulminant hepatitis. N Engl J Med. 1991; 324: 1705-1709.

4. Garg H, Sarin SK, Kumar M, et al. Tenofovir improves the outcome in patients with spontaneous reactivation of hepatitis B presenting as acute-on-chronic liver failure. Hepatology. 2011; 53: 774-780.

5. Lok AS, Lai CL. Acute exacerbation in Chinese patients with chronic hepatitis B virus (HBV) infection. Incidence, predisposing factors and etiology. J Hepatol. 1990; 10: 29-34.

6. Oketani M, Ido A, Tsubouchi $\mathrm{H}$. Changing etiologies and outcomes of acute liver failure: A perspective from Japan. J Gastroenterol Hepatol. 2011; 26 (Suppl 1): 65-71.

7. Chien RN, Lin CH, Liaw YF. The effect of lamivudine therapy in hepatic decompensation during acute exacerbation of chronic hepatitis B. J Hepatol. 2003; 38: 322-327.

8. Sarin SK, Kumar A, Almeida JA, et al. Acute-on-chronic liver failure: consensus recommendations of the Asian Pacific Association for the study of the liver (APASL). Hepatol Int. 2009; 3 : 269-282.

9. Dienstag JL, Perrillo R, Schiff ER, et al. A preliminary trial of lamivudine for chronic hepatitis B infection. N Engl J Med. 1999; 333: 1657-1661.

10. Lai CL, Chien RN, Leung NW, et al. A one-year trial of lamivudine for chronic hepatitis B. Asia Hepatitis Lamivudine Study Group. N Engl J Med. 1998; 339: 61-68.

11. Dienstag JL, Schiff ER, Wright TL, et al. Lamivudine as initial treatment for chronic hepatitis B in the United States. N Engl J Med. 1999; 341: 1256-1263.

12. Potthoff A, Tillmann HL, Bara C, et al. Improved outcome of chronic hepatitis $\mathrm{B}$ after heart transplantation by long-term antiviral therapy. J Viral Hepat. 2006; 13: 734-741.

13. Innaimo SF, Seifer M, Bisacchi GS, et al. Identification of BMS-200475 as a potent and selective inhibitor of hepatitis B virus. Antimicrob Agents Chemother. 1997; 41: 1444-1448.

14. Ono SK, Kato N, Shiratori Y, et al. The polymerase L528M mutation cooperates with nucleotide binding-site mutations, increasing hepatitis B virus replication and drug resistance. J Clin Invest. 2001; 107: 449-455.

15. Yuen MF, Lai CL. Treatment of chronic hepatitis B: evolution over two decades. J Gastroenterol Hepatol. 2011; 26 (Suppl 1): S138-S143.

16. Kanda T, Yokosuka O, Ehata T, et al. Detection of GBV-C RNA in patients with non-A-E fulminant hepatitis by reverse-transcription polymerase chain reaction. Hepatology. 1997; 25: 1261-1265.

17. Kanda T, Yokosuka O, Ikeuchi T, et al. The role of TT virus infection in acute viral hepatitis. Hepatology. 1999; 29: 1905-1908.

18. Kamezaki $\mathrm{H}$, Kanda $\mathrm{T}, \mathrm{Wu} \mathrm{S}$, et al. Emergence of entecavir-resistant mutations in nucleos(t)ide-naïve Japanese patients infected with hepatitis B virus: Virological breakthrough is also dependent on adherence to medication. Scand J Gastroenterol. 2011; 46: 1111-1117. 
19. Wu S, Kanda T, Imazeki F, et al. Hepatitis B virus e antigen downregulates cytokine production in human hepatoma cell lines. Viral Immunol. 2010; 23: 467-476.

20. Usuda S, Okamoto H, Iwanari H, et al. Serological detection of hepatitis B virus genotypes by ELISA with monoclonal antibodies to type-specific epitopes in the preS2-region product. J Virol Methods. 1999; 80: 97-112.

21. Gallego A, Sheldon J, Garcia-Samaniego J, et al. Evaluation of initial virological response to adefovir and development of adefovir-resistant mutations in patients with chronic hepatitis B. J Viral Hepat. 2008; 15: 392-398.

22. Fujiwara K, Yokosuka O, Ehata T, et al. The two different states of hepatitis B virus DNA in asymptomatic carriers: HBe-antigen-positive versus anti-HBe-positive asymptomatic carriers. Dig Dis Sci. 1998; 43: 368-376.

23. Mendes-Correa MC, Pinho JR, Gomes-Gouvea MS, et al. Predictors of HBeAg status and hepatitis B viremia in HIV-infected patients with chronic hepatitis B in the HAART era in Brazil. BMC Infect Dis. 2011; 11: 247.

24. Wong VW, Wong GL, Yiu KK, et al. Entecavir treatment in patients with severe acute exacerbation of chronic hepatitis B. J Hepatol. 2011; 54: 236-242.

25. Sarin SK, Sandhu BS, Sharma BC, et al. Beneficial effects of 'lamivudine pulse' therapy in HBeAg-positive patients with normal ALT. J Viral Hepat. 2004; 11: 552-558.

26. Fujisaki S, Yokomaku Y, Shiino T, et al. Outbreak of infections by hepatitis $\mathrm{B}$ virus genotype $\mathrm{A}$ and transmission of genetic drug resistance in patients coinfected with HIV-1 in Japan. J Clin Microbiol. 2011; 49: 1017-1024.

27. Lindh M, Uhnoo I, Blackberg J, et al. Treatment of chronic hepatitis B infection: An update of Swedish recommendations. Scand J Infect Dis. 2008; 40: 436-450.

28. Seta T, Yokosuka O, Imazeki F, et al. Emergence of YMDD motif mutants of hepatitis $\mathrm{B}$ virus during lamivudine treatment of immunocompetent type B hepatitis patients. J Med Virol. 2000; 60: 8-16.

29. Kusumoto S, Tanaka Y, Ueda R, et al. Reactivation of hepatitis B virus following rituximab-plus-steroid combination chemotherapy. J Gastroenterol. 2011; 46: 9-16.

30. Yeo W, Johnson PJ. Diagnosis, prevention and management of hepatitis B virus reactivation during anticancer therapy. Hepatology. 2006; 43: 209-220. 